\title{
ESTUDOOS JURISPRUDENCAALES
}

\section{LA DEMARCACIÓN TERRITORIAL DE LA MEDIDA CAUTELAR COMO ELEMENTO COMPETENCIAL. Sentencia del Juzgado de lo Social de}

Sevilla número 7, de 01 de abril de 2020

THE TERRITORIAL DEMARCATION OF THE PRECAUTIONARY MEASURE AS A

COMPLETENTIAL ELEMENT. Sentence of the Court of the Social of Seville number 7 , of April 1, 2020

Francisca Moreno Romero

Profesora Ayudante Doctora

Universidad Complutense de Madrid

fmorenoromero@pdi.ucm.es ORCID 0000-0002-3657-2150

Recepción de trabajo: 07-07-2020 - Aceptación: 24-07-2020

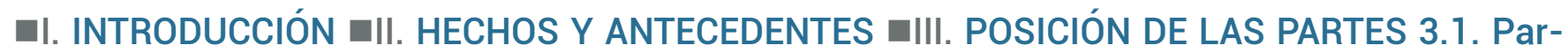
te demandante 3.2. Parte demandada 3.3. Posición del Ministerio Fiscal 口IV. RAZONAMIENTO JURÍDICO. ■V. LA EXCEPCIONALIDAD DE LA SITUACIÓN Y SU INFLUENCIA EN LA DOCTRINA DEL TRIBUNAL SUPREMO Y DEL TRIBUNAL SUPERIOR DE JUSTICIA DE ANDALUCÍA. 


\section{RESUMEN}

Los distintos espacios competenciales tanto por razón de la materia -a los que se vinculan las peticiones de medidas cautelares (derechos fundamentales, prevención de riesgos laborales...) - , como por razón del ámbito territorial de aplicación de las mismas, constituyen el núcleo central de la sentencia. No obstante, y desde una perspectiva más general, la doctrina del Tribunal Supremo y del Tribunal Superior de Justicia de Andalucía recogen la excepcionalidad de la situación y su influencia a la hora de denegar las medidas cautelares.

PALABRAS CLAVE: prevención de riesgos laborales; medidas cautelarísimas; COVID-19; personal sanitario

\section{ABSTRACT}

The different areas of competence both by reason of the matter - to which there quests for precautionary measures (fundamental rights, prevention of occupational risks, etc.)-, and by reason of the territorial scope of their application, are the central nucleusof the judgment. However, and from a more general perspective, the doctrine of the Supreme Court and the Superior Court ofJustice of Andalusia reflect the exceptional nature of the situation and its influence when it comes to denying precautionary measures.

KEYWORDS: prevention of occupational risks; precautionary measures; COVID-19; healthpersonnel 


\section{INTRODUCCIÓN}

La Sentencia del juzgado de lo Social núm. 7 de Sevilla, en el procedimiento de medidas cautelares 319/2020, fue dictada en el singular contexto provocado a partir de la declaración del estado de alarma por el Real Decreto 463/2020, de 14 de marzo, para la gestión de la situación de la crisis sanitaria ocasionada por la COVID-19.

En ese escenario, como bien se conoce, y en las particulares fechas en que fue presentada la demanda por el SINDICATO MÉDICO ANDALUZ FEDERACIÓN, el día 25 de marzo de 2020, la escasez de medios de protección y material técnico necesario para realizar las tareas de atención y tratamiento médicos a los enfermos afectados por la COVID-19, previniendo con ello el riesgo de contagio,eran notorias. La falta de batas impermeables, mascarillas FPP2, gafas de protección y contenedores grandes de residuos conllevaba la desprotección en la práctica de los profesionales sanitarios. Por ello, el Sindicato médico solicita medida cautelar consistente en que se garantice la protección eficaz en materia de seguridad y salud en el trabajo de los profesionales sanitariosen orden a lo establecido por los artículos 14, 15 y 17 de la Ley 31/1995, de Prevención de Riesgos Laborales (LPRL), así como por los artículos 15 y 43.1 de la Constitución Española (CE).

El Juzgado de lo social núm. 7 de los de Sevilla resuelve dictando sentencia en la que aprecia su falta de competencia, estableciendo que corresponde su conocimiento a la Sala de lo Social del Tribunal Superior de Justicia de Andalucía, como analizaremos a continuación.

\section{HECHOS Y ANTECEDENTES}

Con fecha 14 de marzo de 2020 se publicó el Real Decreto 463/2020, por el que se declaró el estado de alarma para la gestión de la situación de crisis sanitaria ocasionada por el COVID-19, valiéndose de la previsión contenida para estas situaciones en el art. 116 de la CE.

La emergencia sanitaria que provocó la llegada del coronavirus resultó de una virulencia extrema siendo las resultas, entre otras, el desabastecimiento de equipos de protección eficaz necesarios para su uso por el personal sanitario en centros en los que, potencialmente, se atendía a ciudadanos afectados por este virus, ya fueren estos centros hospitalarios, servicios de emergencia, centros de salud de atención primaria u otros.

Dada esta circunstancia, por otro ladogeneralizada en el país, el Sindicato Médico Andaluz Federación considera que la situación reviste tal urgencia que se hace necesario solicitar inaudita parte la adopción de medidas cautelarísimas que garanticen la eficaz protección de los profesionales sanitarios en materia de seguridad y salud en sus puestos de trabajo. Con ella se requiere a la Consejería de Salud y Familias de la Junta de Andalucía y al Servicio Andaluz de Salud para que provea con carácter urgente e inmediato, en el término de 24 horas y en todos los Centros hospitalarios, Centros Asisten- 
LA DEMARCACIÓN TERRITORIAL DE LA MEDIDA CAUTELAR COMO ELEMENTO COMPETENCIAL

ciales de Atención primaria, Servicios de Emergencias, Servicios de Asistencial Rural, centros con pacientes institucionalizados y cualesquiera otras dependencias habilitadas para uso sanitario -ya sean de carácter público o privado-, para que sean dotados con los equipos de protección debidos para hacer frente a la situación de emergencia sanitaria.

\section{POSICIÓN DE LAS PARTES}

\section{1. Parte demandante}

Con base en el art. 79 de la LRJS, que regula la adopción de medidas cautelares para asegurar la efectividad de la tutela judicial que pudiera acordarse en sentencia, y que a su vez se remite a lo dispuesto en los arts. 721 a 747 de la LEC, el SINDICATO MÉDICO ANDALUZ presenta la solicitud de medidas cautelarísimas inaudita parte, contra la Consejería de Salud y Familias de la Junta de Andalucía y el Servicio Andaluz de Salud, para que en el plazo de 24 horas provea a todos los centros habilitados para uso sanitario, tanto públicos como privados, de los equipos de protección necesarios para atender las necesidades de atención y tratamiento ante la situación de crisis sanitaria provocada por la COVID-19. Ello en cumplimiento del deber asumido por la Administración sanitaria a través en los arts. 14, 15 y 17 de la Ley 31/1995 de Prevención de Riesgos Laborales y en los artículos 15 y 43.1 de la CE.

Con esa finalidad, se presenta demanda sobre tutela de derechos fundamentales instando la adopción de medidas cautelares alegando (razonamiento jurídico $1^{\circ}$ ):

"que, tras la entrada en vigor del Real Decreto 463/20202, de 14 de marzo, por el que se declara elestado de alarma para la gestión de la situación de la crisis sanitaria ocasionada por el COVID-19, el personalsanitario se encuentre total o insuficientemente protegido ante la acción de este patógeno viral, sin que se lenutra de los elementos y condiciones necesarias para evitar el contagio al que se ven expuestos durante el tratamiento y cuidado de las personas afectadas por esta enfermedad. Señala, el grave riesgo la salud de lostrabajadores de la sanidad y de los propios ciudadanos que acuden a los centros asistenciales del territorio dela Comunidad Autónoma, con la consiguiente conculcación de su derecho fundamental a la propia vida y a laintegridad física. Interesándose "MEDIDAS CAUTELARÍSIMAS "INAUDITA PARTE" en procedimiento de TUTELADE DERECHOS FUNDAMENTALES contra Ia CONSEJERIA DE SALUD Y FAMILIAS DE LA JUNTA DE ANDALUCIA,SERVICIO ANDALUZ DE SALUD, $y$, acreditada la concurrencia de razones de urgencia, sin más trámites, dicte AUTO, por el que con estimacióntotal de la misma, acuerde las medidas cautelarísimas de requerir a la Administración demandada a finque en cumplimiento de las recomendaciones de la Organización Mundial de la Salud, de lo establecido enel Real Decreto 463/2020, de 14 de marzo, por el que se declara el estado de alarma, y en atención a la 
LA DEMARCACIÓN TERRITORIAL DE LA MEDIDA CAUTELAR COMO ELEMENTO COMPETENCIAL

directa aplicación de la Ley de Prevención de Riesgos Laborales y Reglamento de Desarrollo, para que proveacon carácter urgente e inmediato, en el término de 24 horas, en todos los Centros hospitalarios, Centrosasistenciales de Atención Primaria, Servicios de Emergencias, Servicios de Asistencial Rural, centros conpacientes institucionalizados, ya sean públicos o privados y cualesquiera otras dependencias habilitadas parauso sanitario, BATAS IMPERMEABLES, MASCARILLAS FPP2, FPP3, GAFAS DE PROTECCIÓN y CONTENDEROSGRANDES DE RESIDUOS".

\subsection{Parte demandada}

El Servicio Andaluz de Salud alega falta de competencia objetiva del Juzgado de lo Social, correspondiéndolo éstaa la Sala de lo Social del Tribunal Superior de Andalucía, así como falta de legitimación activa del Sindicato Médico Andaluz Federación.

Por su parte, la Junta de Andalucía alega falta de competencia del Juzgado, dada la solicitud de adopción de medidas cautelares en relación con la tutela de derechos fundamentales, señalando como afectados los derechos a la vida y a la integridad física protegidos por el art. 15 CE. Señala así la Junta que el ámbito de afectación es todo el territorio de la Comunidad Autónoma de Andalucía, por cuanto el solicitante no ha limitado su petición a la provincia de Sevilla. De esta forma y de acuerdo con lo establecido en los arts. $2 \mathrm{f}$ (tutela de derechos fundamentales) y 7 a) (que especifica que "cuando extiendan sus efectos a un ámbito territorial superior al de la circunscripción de un Juzgado de lo Social y no superior al de la Comunidad Autónoma) de la LRJS, la competencia correspondería a la Sala de lo Social del TSJ de Andalucía, sede de Sevilla en atención al domicilio del sindicato demandante.

Al no considerar competente al Juzgado de lo Social, por lo visto, la Junta de Andalucía entiende que tampoco lo es aquél para resolver sobre las medidas cautelares, por cuanto el art. 723.1 LEC determina que será competente el órgano judicial "que esté conociendo del asunto en primera instancia o, si el proceso no se hubiese iniciado, al que sea competente para conocer de la demanda principal".

\subsection{Posición del Ministerio Fiscal}

Por su parte, el Ministerio Fiscal alega que nos encontramos ante un Conflicto colectivopues según establece el art. 153.1 LRJS, se tramitarán bajo esta modalidad "las demandas que afecten a intereses generales de un grupo genérico de trabajadores o a un colectivo genérico susceptible de determinación individual y que versen sobre la aplicación e interpretación de una norma estatal", como es el caso, en el que el conflicto afecta al ámbito de toda la Comunidad Autónoma de Andalucía, según la demanda. 


\section{RAZONAMIENTO JURÍDICO}

A través de su sentencia, el Juzgado de lo Social aprecia su falta de competencia en el asunto por lo que, consecuentemente, no concede la medida cautelar interesada por el Sindicato Médico Andaluz Federación, determinando que el conocimiento de la cuestión corresponde a la Sala de lo Social del Tribunal Superior de Justicia de Andalucía.Esto es, el primer análisis del procedimiento que realiza el Juzgado tiene una necesaria perspectiva competencial. Por elloestablece su falta de competencia en aplicación de los artículos de la LRJS 2.f), referido a la tutela de derechos fundamentales y art. 7.a), que determina la competencia de la Sala de lo Social del TSJ que corresponda, cuando los efectos se extiendan en un ámbito territorial superior al de la circunscripción de un Juzgado de los Social y no superior al de la Comunidad Autónoma de que se trate.

A esta conclusión llega el Juzgado por diversos motivos. En primer lugar, el art. 723.1 LEC determina que "será tribunal competente para conocer de las solicitudes sobre medidas cautelares el que esté conociendo del asunto en primera instancia o, si el proceso no se hubiese iniciado, el que sea competente para conocer de la demanda principal". Si bien en el caso que se presenta ante el Juzgado se trata del ejercicio de una acción para la tutela de derechos fundamentales, el Juzgado entiende que del contenido fáctico de la demanda se trata, en realidad, de una reclamación en materia de prevención de riesgos laborales por incumplimiento de determinados preceptos de la Ley 31/1995 PRL, por parte de la Administración concernida.

De esta ubicación material del procedimiento, deviene la necesidad de atender a aquello que se solicita en la demanda, esto es, el requerimiento a la Junta de Andalucía para que proporcione los equipos de protección personal en materia de prevención de riesgos laborales al personal sanitario y a los centros hospitalarios, en general. De esta forma, al entender del Juzgado, resulta de aplicación lo dispuesto por el art. 2. e) de la LRJS.

Así es, como cita la propia sentencia, en su razonamiento jurídico segundo, la Ley Reguladora de la Jurisdicción Social incluyó la atribución al orden jurisdiccional social en materia de prevención de riesgos laborales, cuestión que no estaba prevista en la anterior Ley en la materia, con la intención de atribuir al orden jurisdiccional el conocimiento más completo de la materia social. De esta forma, el orden social se convierte en el garante del cumplimiento de la normativa de prevención de riesgos laborales, asignándosele competencias con carácter pleno, cuestión que implica la inclusión de funcionarios o personal estatutario, pudiendo éstos plantear ante aquel orden jurisdiccional sus reclamaciones en igualdad de condiciones que los trabajadores por cuenta ajena, incluyéndose además competencias sobre medidas cautelares. Se cubre con esta previsión normativa, el amparopor la jurisdicción social de las causasde responsabilidad de deberes preventivos más allá de las empresas privadas, alcanzando también a las Administraciones Públicas.

Sirve como sustento fundamental a estos efectos, la importante STS de 24 de junio de 2019 ( $n$. rec.123/2018), en cuyo Fundamento de Derecho Tercero se establece la jurisprudencia sobre la atribu- 
LA DEMARCACIÓN TERRITORIAL DE LA MEDIDA CAUTELAR COMO ELEMENTO COMPETENCIAL

ción al orden social de la materia de prevención de riesgos laborales. Tras destacar el papel unificador de la LRJS.2011, en cuanto a conocimiento completo de la materia social, reconoce que el ejercicio único de cualquier títulopor parte del trabajador o empleado, cuando la vulneración del derecho alegada tenga conexión directa con la prestación de servicios, ha venido a corregir el denominado "peregrinaje de jurisdicciones" al que se veía sometido, logrando con ello una "mayor seguridad jurídica y celeridad en la respuesta judicial, al tiempo que (alcanza) una pretendida mayor calidad en las respuestas judiciales al resolverse por órganos cada vez más especializados (...)". La LRJS atribuye con carácter pleno al orden jurisdiccional social el conocimiento de los litigios sobre aplicación de normativa de prevención de riesgos laborales también cuando afecten al personal funcionarial o estatutario de las Administraciones Públicas empleadoras, por lo que compete a esta jurisdicción cualquier impugnación frente a la actuación de las Administraciones Públicas en la referida materia, como es el caso. Esta protección que garantiza el juez social se extiende también con carácter previo a la posible causación del daño, tal y como se desprende de la Exposición de motivos de la LRJS que indica que "no sólo se fortalecen los instrumentos judiciales para proteger a las víctimas de accidentes de trabajo, sino que además se disponen los recursos para hacer efectiva la deuda de protección del empresario y la prevención de riesgos laborales".

Justificada por el Juzgado la atribución del orden social en materia de Prevención de riesgos laborales' procede, a continuación, a determinar que, si bien el cauce procesal utilizado no es el adecuado,

1 Resulta de gran interés, a los efectos, el estudio respecto de la competencia jurisdiccional en situaciones similares de solicitud de medidas cautelarísimas ante el desabastecimiento de material sanitario y de protección de los profesionales sanitarios, cuerpos de policía, etc. derivadas a partir del establecimiento del estado de alarma por la pandemia de la COVID-19, desarrollado por CASAS BAAMONDE, M.A. y ÁNGEL QUIROGA, M.Así, respecto de la competencia de la Sala Contencioso-administrativa respecto de la solicitud inaudita parte de medida cautelarisima objeto de la STS que analizan (Sala Tercera, Sección Cuarta, de 25 de marzo de 2020)destacan que la Sala "resuelve realmente sobre su competencia funcional, pues las medidas preventivas solicitadas habían de requerirse al Ministerio de Sanidad, y la Sala de lo Contencioso-administrativo del Tribunal Supremo conoce en única instancia de los recursos frente a actos y disposiciones del Consejo de Ministros y de las Comisiones Delegadas del Gobierno [artículo 12.1.a) de la LCA]. Salva el "obstáculo" mediante la inserción de las medidas requeridas "en el marco creado por la declaración del estado de alarma", en que el Gobierno es la única autoridad competente, conforme al artículo 4.1 del Real Decreto 463/2020, de 14 de marzo, y el Ministro de Sanidad es autoridad competente que actúa por delegación del Gobierno para el ejercicio de las funciones previstas en dicho Real Decreto "bajo la superior dirección del Presidente del Gobierno" (artículo 4.2). Considera la Sala la actuación que se requiere del Ministerio de Sanidad por la confederación sindical demandante como propia del Ministro de Sanidad y la de éste como propia del Consejo de Ministros por delegación en el estado de alarma, con las consecuencias de todo orden que de esa identificación se derivan. Resuelve así la Sala su competencia funcional". Posteriormente, añaden que deben referirse, no obstante, y como contrapunto "a decisiones del orden jurisdiccional social, que han afirmado su jurisdicción para el conocimiento de la petición de medidas cautelarísimas idénticas a las solicitadas a la Sala Tercera del Tribunal Supremo, aunque no han sido dirigidas frente al Ministerio de Sanidad. Otras peticiones también cautelarísimas, también en materia de prevención de riesgos laborales, y también dirigidas al Ministerio de Sanidad, han sido enjuiciadas por la jurisdicción social. CASAS BAAMONDE, M.A. y ÁNGEL QUIROGA, M. "Dualidad de jurisdicciones, contencioso-administrativa y social, en el estado de alarma. La prevención de riesgos laborales del personal sanitario en la emergencia de la pandemia de COVID-19 ante el desabastecimiento de medios de protección de la salud. Solicitud de medidas cautelarísimas inaudita parte de provisión de medios de protección sanitaria a hospitales y centros asistenciales", en Revista de Jurisprudencia Laboral (RJL), ISSN-e 2659-787X, N. ${ }^{\circ}$ 3, 2020. 
LA DEMARCACIÓN TERRITORIAL DE LA MEDIDA CAUTELAR COMO ELEMENTO COMPETENCIAL

sí procede aplicar al caso, en orden al contenido real de la pretensión solicitada, lo establecidopor el art. 179.4 LRJS en cuanto a tramitación, cuyo tenor es:

\begin{abstract}
“Sin perjuicio de lo dispuesto en el artículo 81, el juez o tribunal rechazará de plano las demandas que no deban tramitarse con arreglo a las disposiciones de este Capítulo y no sean susceptibles de subsanación, advirtiendo al demandante del derecho que le asiste a promover la acción por el cauce procesal correspondiente. No obstante, el juez o la Sala dará a la demanda la tramitación ordinaria o especial si para el procedimiento adecuado fuese competente y la demanda reuniese los requisitos exigidos por la ley para tal clase de procedimiento".
\end{abstract}

Al respecto, es de interés lo recogido por el inciso segundo, esto es, el órgano judicial debe aplicar su contenido y dar al procedimiento la tramitación que corresponda, cuestión que aborda el Juzgado.

En este sentido, el Juzgado aplica la reiterada jurisprudencia que establece la adecuación del procedimiento de tramitación y que queda recogida, entre otras, en la STS de 14 de junio de 2002 (N. ${ }^{\circ} \mathrm{Rec}$. 1192/2001). Así es, en su Fundamento de derecho Tercero, párrafo segundo, se refiere que:

"Ya hay doctrina reiterada de esta Sala sobre la cuestión tratada, que tiene su reflejo, entre otras, en la sentencia de 27 de mayo de 2002, que siguió la doctrina proclamada en las sentencias de 6 de octubre de 1997, 26 de junio de 1998, 20 de junio de 2000 y otras, en las que se ha dicho que "lo decisivo a efectos de la adecuación del procedimiento no es que la pretensión deducida esté correctamente fundada y deba ser estimada, sino que se afirme por el demandante la existencia de una violación de un derecho fundamental. Si no existe la vulneración alegada, o si lo que se produce es una infracción simple del ordenamiento jurídico sin relevancia en la protección constitucional del derecho fundamental invocado, la consecuencia de la limitación de conocimiento que rige en la modalidad procesal será la desestimación de la demanda, sin perjuicio en su caso de la conservación de la acción para alegar la eventual existencia de una infracción de legalidad ordinaria en otro proceso"; abundando en esa misma idea, la sentencia de 18 de noviembre de 1997 declaró que "el hecho de que el órgano judicial competente considere que no se ha producido la lesión del derecho invocado no afecta a la adecuación del procedimiento, pues la consecuencia de esa operación será, de acuerdo con el principio de cognición limitada propia de esta modalidad procesal, la desestimación de la pretensión de tutela, sin perjuicio de la acción ordinaria en el proceso correspondiente, pero no la declaración de inadecuación de un procedimiento en el que formalmente se ha instado de forma correcta". La doctrina expuesta presupone que, si la parte interesada acude a la modalidad procesal de tutela del derecho de libertad sindical, exponiendo los hechos que estima lesivos a tal derecho, y con la pretensión de que se ponga remedio a la violación denunciada, no cabe entender que el procedimiento seguido es inadecuado, a pesar de que se desestime la demanda al resolver sobre el fondo de la cuestión". 
LA DEMARCACIÓN TERRITORIAL DE LA MEDIDA CAUTELAR COMO ELEMENTO COMPETENCIAL

Por ello el Juzgado aplica lo dispuesto en el art. 179.4, inciso segundo, de la LRJS y da al procedimiento la tramitación que corresponde. Así, motivado por las evidentes razones de urgencia, gravedad y necesidad la tramitación debe ajustarse a un procedimiento de solicitud de medidas de prevención de riesgos laborales, siendo competente para ello la Sala de lo Social del TSJ por pretender que los efectos de la medida solicitada se extiendan a un ámbito territorial superior al de la circunscripción de un Juzgado de lo Social y no superior al de la Comunidad Autónoma.

\section{LA EXCEPCIONALIDAD DE LA SITUACIÓN Y SU INFLUENCIA EN LA DOCTRINA DEL TRIBUNAL SUPREMO Y DEL TRIBUNAL SUPERIOR DE JUSTICIA DE ANDALUCÍA}

Pocos días después de que viese la luz el Auto que se comenta en el presente capítulo, se dictó por el TSJ-Andalucía el Auto 3/2020 de 3 de abril, en el que se deniega la medida cautelarísima solicitada por la representación procesal de Central Sindical Independiente y de Funcionarios frente a Consejería de Salud de la Junta de Andalucía y Servicio Andaluz de Salud. La resolución cierra el procedimiento ya que contra la misma no cabrá recurso alguno, de conformidad con lo dispuesto en el artículo 733.2 párrafo $2^{\circ}$ de la Ley de Enjuiciamiento Civil.

Como era previsible la Sala comienza por determinar de oficio los espacios competenciales, en una triple dimensión.

En primer lugar se afirma que "es competente esta Sala de lo Social de conformidad con lo dispuesto en el artículo 2 e) de la Ley Reguladora de la Jurisdicción Social, en relación con el artículo 2.5 de la Ley Orgánica del Poder Judicial, pues se trata de una pretensión cautelar promovida por un sindicato para el cumplimiento de las obligaciones legales en materia de prevención de riesgos laborales, de conformidad con lo decidido en la sentencia de la Sala de lo Social del Tribunal Supremo de 24 de junio de 2019 -recurso 123/2018- , en la que se sienta el criterio de la "vis atractiva" del orden social respecto de las pretensiones en materia de prevención de riesgos laborales, con independencia de la naturaleza del vínculo; laboral, funcionarial o estatutario de la Seguridad Social(criterio también ha sido confirmado por la Sala de Conflicto de Competencia del Tribunal Supremo en el auto 12/2019, de 16 de mayo -recurso 22/2018-) .

Por otro lado y en cuanto a la competencia objetiva, se razona que si bien el artículo 2 e) de la Ley Reguladora de la Jurisdicción Social no encuentra mención alguna en el artículo 7 de la misma Ley, que es el que atribuye la competencia objetiva a la Sala de lo Social de los Tribunales Superiores de Justicia para determinados procesos [(art. 2 f), g) h), j), k) y l)], será competente ésta cuando extiendan sus efectos a un ámbito superior al de la circunscripción de un Juzgado y no superior al de la Comunidad Autónoma. Dicho esto, existen dos argumentos que nos llevan a asumir la competencia objetiva 
LA DEMARCACIÓN TERRITORIAL DE LA MEDIDA CAUTELAR COMO ELEMENTO COMPETENCIAL

como propia de esta Sala; en primer lugar, el procedimiento adecuado para sustanciar una demanda colectiva de este tipo, que no sería otro que el procedimiento de conflicto colectivo ( artículo $2 \mathrm{~g}$ ) de la Ley Reguladora de la Jurisdicción Social) para el que esta Sala goza de competencia expresamente atribuida en el artículo 7; en segundo lugar, el ámbito de extensión del conflicto, pues trasciende la circunscripción de los Juzgados de lo Social sin superar el de la Comunidad Autónoma de Andalucía [(artículo 7 a)].

Finalmente, en cuanto a la competencia funcional, esta Sala la tiene en virtud de los artículos 61 y 723 de la Ley de Enjuiciamiento Civil, pues gozando de competencia objetiva para conocer sobre el pleito principal la tiene también para resolver sobre sus incidencias, entre ellas, las medidas cautelares

La Sala que desestima las medidas cautelares, afirma que “...no hay ninguna acreditación de que no se esté suministrando el indicado material ni de que las Administraciones estén incurriendo en el citado incumplimiento, ni de que tengan material que no estén repartiendo, siendo notorios, por un lado, la insuficiencia en las Administraciones del material reclamado y, por otro, los esfuerzos de sus responsables para conseguirlo".

En este orden, el Auto hace suyos los razonamientos contenidos en el auto de 25 de marzo de 2020 -recurso 88/2020- de la Sección Cuarta de la Sala de lo Contencioso-Administrativo del Tribunal Supremo, en el sentido de que "la Sala es consciente de la emergencia en que nos encontramos y también de la labor decisiva que para afrontarla están realizando especialmente los profesionales sanitarios. Tampoco desconoce que deben contar con los medios necesarios para que la debida atención a los pacientes que están prestando de forma abnegada no ponga en riesgo su propia salud, ni la de las personas con las que mantengan contacto. Y coincide en que se han de hacer cuantos esfuerzos sean posibles para que cuenten con ellos. Sucede, sin embargo, que no consta ninguna actuación contraria a esa exigencia evidente y sí son notorias las manifestaciones de los responsables públicos insistiendo en que se están desplegando toda suerte de iniciativas para satisfacerla. En estas circunstancias, como hemos dicho, no ha fundamento que justifique la adopción de la medida provisionalísima indicada. Es decir, nos han traído a las actuaciones elementos judiciales asequibles, los únicos que cabe considerar en el proceso, en cuya virtud deba acordarse sin oír a la Administración".

Por último y si bien se desestima la medida cautelarísima, el Auto plantea la posibilidad de que el sindicado demandante pueda formular demanda de procedimiento de conflicto colectivo en materia de prevención de riesgos laborales, con la correspondiente medida cautelar, de conformidad con el artículo 79 de la Ley Reguladora de la Jurisdicción Social que, a su vez, se remite a los artículos 721 a 747 de la Ley de Enjuiciamiento Civil.

Los distintos espacios competenciales, tanto por razón de la materia a los que se vinculan la petición de medidas cautelares (derechos fundamentales, prevención...) como por razón del ámbito territorial de aplicación de las mismas, constituyen el núcleo central de la sentencia. No obstante, y desde una perspectiva mas general, la doctrina del TS y del TSJ-Andalucía recogen la excepcionalidad de la situación y su influencia a la hora de denegar las medidas cautelares. 


\section{BIBLIOGRAFÍA}

CASAS BAAMONDE, M.A. y ÁNGEL QUIROGA, M. "Dualidad de jurisdicciones, contencioso-administrativa y social, en el estado de alarma. La prevención de riesgos laborales del personal sanitario en la emergencia de la pandemia de COVID-19 ante el desabastecimiento de medios de protección de la salud. Solicitud de medidas cautelarísimas inaudita parte de provisión de medios de protección sanitaria a hospitales y centros asistenciales", en Revista de Jurisprudencia Laboral (RJL), ISSN-e 2659-787X, N. ${ }^{\circ} 3,2020$.

LÓPEZ ANIORTE, María del Carmen. Ampliación del marco competencial del orden social: ¿hacia la unidad de jurisdicción?. 103, 2013.

GIL PLANA, "La razón de ser del procedimiento Laboral I y II", Revista Española de Derecho del Trabajo num. 172/2015 parte Estudios. Editorial Aranzadi, S.A.U., Cizur Menor. 2015. 